\title{
Structure and Polarization Properties of Zn-Nb Films Formed on Steel Sheet by Sputtering
}

\author{
Hiroshi KUBOYAMA,${ }^{1)}$ Hiroaki NAKANO, ${ }^{2)}$ Satoshi OUE, ${ }^{2)}$ Hisaaki FUKUSHIMA, ${ }^{21}$ Masataka MASUDA ${ }^{2)}$ and \\ Shunichi HASHIMOTO ${ }^{3)}$ \\ 1) Graduate School of Engineering, Kyushu University, 744, Motooka, Nishi-ku, Fukuoka-shi 819-0395 Japan. \\ 2) Faculty of Engineering, Kyushu University, 744, Motooka, Nishi-ku, Fukuoka-shi 819-0395 Japan. \\ 3) CBMM Asia Co., Ltd., 4-1-4, Akasaka, Minato-ku, Tokyo 107-0052 Japan.
}

(Received on February 13, 2006; accepted on April 26, 2006; originally published in Tetsu-to-Hagané, Vol. 92, 2006, No. 1, pp. 16-20)

\begin{abstract}
$\mathrm{Zn}-\mathrm{Nb}$ films were formed on a steel sheet by helicon plasma sputtering in an argon gas atmosphere at 1.0 Pa, at RF power of $50 \mathrm{~W}$ and DC power of $50 \mathrm{~mA}$. The structure and polarization properties of these films were studied using EPMA, X-ray diffraction and polarization curve measurements. Zn plate-like crystals in $\mathrm{Zn}-\mathrm{Nb}$ films decreased with increasing $\mathrm{Nb}$ content, resulting in a smooth surface over the entire film at $\mathrm{Nb}$ content of 30 mass\% and above. The preferred orientation plane of $\mathrm{Zn}$ plate-like crystals was (0002) at 0 mass $\% \mathrm{Nb}$, while the orientation indices of $(10 \overline{1} 1)$ and $(10 \overline{1} 0) \mathrm{Zn}$ increased with rising $\mathrm{Nb}$ content. At 30-60 mass\% Nb, the X-ray diffraction spectra showed a halo pattern characteristic of an amorphous structure. The corrosion current of $\mathrm{Zn}-\mathrm{Nb}$ films, which was determined by polarization curves in $3 \% \mathrm{NaCl}$ solution, decreased with increasing $\mathrm{Nb}$ content to reach a minimum value at 30-60 mass\% $\mathrm{Nb}$, corresponding to an amorphous structure.
\end{abstract}

KEY WORDS: Zn-Nb; sputtering; polarization property; amorphous structure.

\section{Introduction}

Zinc coating on steel sheet is produced by hot dip galvanizing or electroplating. Electroplating has been applied to the production of pure $\mathrm{Zn}$ and $\mathrm{Zn}-\mathrm{Ni}$ alloy coated steel sheets, and $\mathrm{Zn}-\mathrm{Cr}$ electroplating ${ }^{1-3)}$ has also been studied due to its excellent corrosion resistance. Substances of environmental concern and more noble metals than $\mathrm{Fe}$ which are difficult to recycle need to be avoided when designing highly corrosion-resistant $\mathrm{Zn}$ alloy films. It is known from the investigation of $\mathrm{Zn}$ alloy films produced by hot dip galvanizing and dry process coating that less noble metals than $\mathrm{Zn}$, such as $\mathrm{Mg}, \mathrm{Al}$ and $\mathrm{Ti}$ improve the corrosion resistance of the $\mathrm{Zn}$ alloy films. ${ }^{4-10)}$ These metals are not regarded as environmental pollutants. $\mathrm{Nb}$ is a less noble metal and is expected to improve the corrosion resistance of $\mathrm{Zn}$ alloy films. However, there have been very few studies on the corrosion properties of $\mathrm{Zn}-\mathrm{Nb}$ alloy films. Since the melting point of $\mathrm{Nb}$ is $2743 \mathrm{~K}$, much higher than that of $\mathrm{Zn}$, $1180 \mathrm{~K}$, it would be difficult to produce $\mathrm{Zn}-\mathrm{Nb}$ alloy coating by hot dip galvanizing. Therefore, in this study, $\mathrm{Zn}-\mathrm{Nb}$ alloy films were formed on steel sheets by sputtering, and the structure and polarization properties of the films were investigated.

\section{Experimental}

Commercial polycrystalline low carbon Al-killed steel sheet $\left(14 \times 14 \mathrm{~mm}^{2}\right.$ with a thickness of $\left.1 \mathrm{~mm}\right)$ was used as the substrate. Each substrate was polished with emery papers (Nos. 600, 1500 and 2000) and buffed to mirror smoothness. The substrate was then degreased in acetone by ultrasonic cleaning prior to sputtering. Figure 1 shows the apparatus for helicon plasma sputtering used in this study. Zn plate (99.99 mass\%) and $\mathrm{Nb}$ plate (99.9 mass\%) with a thickness of $1 \mathrm{~mm}$ were given a fan-like shape with a radius of $3.81 \mathrm{~cm}$ as shown in Fig. 1 and used as targets for sputtering. The area ratio of $\mathrm{Zn}$ to $\mathrm{Nb}$ in the target was varied to obtain the $\mathrm{Zn}-\mathrm{Nb}$ alloy films with different compositions. Two substrates were placed parallel to the target at a distance of $18 \mathrm{~cm}$. During sputtering, temperature of the substrate was about $373 \mathrm{~K}$. After the chamber had been evacuated to $4 \times 10^{-4} \mathrm{~Pa}$ using a rotary pump and a turbomolecular pump, Ar gas was introduced into the chamber until pressure reached $1.0 \mathrm{~Pa}$. $\mathrm{Zn}-\mathrm{Nb}$ alloy films were formed on two substrates simultaneously by sputtering for $2 \mathrm{~h}$ at RF power of $50 \mathrm{~W}$ and DC power of $50 \mathrm{~mA}$.

The alloy films formed were dissolved with hydrofluoric acid and the concentrations of $\mathrm{Zn}$ and $\mathrm{Nb}$ were determined by ICP to calculate the alloy composition and the coating weight. The morphology of the $\mathrm{Zn}-\mathrm{Nb}$ films were observed $\mathrm{SEM}$, and the distribution of $\mathrm{Zn}$ and $\mathrm{Nb}$ was visualized by EPMA. Analysis by X-ray diffraction was also carried out. The crystal orientation of $\mathrm{Zn}$ was determined using Willson and Rogers' method ${ }^{11)}$ with an X-ray diffraction intensity of (0002) to the $(11 \overline{2} 2)$ planes. The polarization curves from less noble to more noble direction were obtained using the potential sweep rate of $1.0 \mathrm{mV} \mathrm{s}^{-1}$ in oxygen-saturated $3 \%$ 
$\mathrm{NaCl}$ solution at $40^{\circ} \mathrm{C}$. A saturated $\mathrm{Ag} / \mathrm{AgCl}$ reference electrode $\left(0.199 \mathrm{~V} v s\right.$. NHE, $\left.25^{\circ} \mathrm{C}\right)$ was used for measurement. Then, the potentials were plotted with reference to NHE. The corrosion current density and the corrosion potential of $\mathrm{Zn}-\mathrm{Nb}$ films were obtained by Tafel's plot extrap-

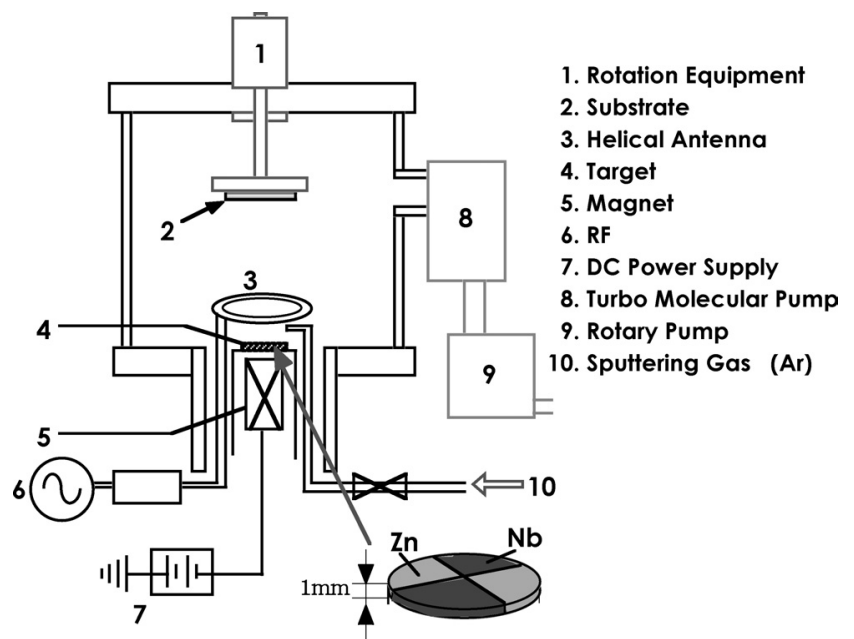

Fig. 1. Apparatus for helicon plasma sputtering.

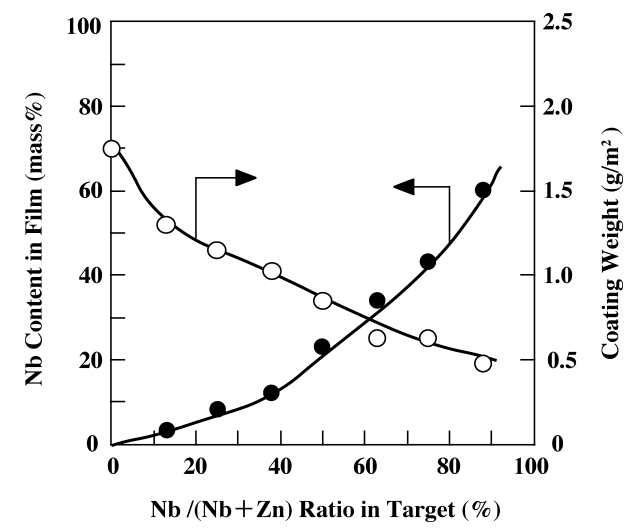

Fig. 2. Effect of $\mathrm{Nb} /(\mathrm{Nb}+\mathrm{Zn})$ ratio in target on the $\mathrm{Nb}$ content and the coating weight of $\mathrm{Zn}-\mathrm{Nb}$ films. olation method. The $\mathrm{Zn}-\mathrm{Nb}$ films were formed simultaneously on two substrates. One was subjected to composition analysis by ICP and the other to polarization measurement. Then relationship between $\mathrm{Zn}-\mathrm{Nb}$ alloy composition and the corrosion current density or the corrosion potential were investigated.

\section{Results and Discussion}

\subsection{Composition of $\mathbf{Z n}-\mathrm{Nb}$ Films}

Figure 2 shows the relationship between the $\mathrm{Nb}$ area ratio of the target and the $\mathrm{Nb}$ content and the coating weight of $\mathrm{Zn}-\mathrm{Nb}$ films formed by sputtering. The $\mathrm{Nb}$ content in the films increased with increasing $\mathrm{Nb}$ area ratio of the target, indicating that $\mathrm{Zn}-\mathrm{Nb}$ alloy films of various composition can be produced by changing the area ratio of the target. The $\mathrm{Nb}$ content in the films was considerably smaller than that in the target, suggesting that $\mathrm{Nb}$ was less likely to be deposited than $\mathrm{Zn}$. In fact, the maximum sputtering ratios of $\mathrm{Zn}$ and $\mathrm{Nb}$ were reported to be 16 atoms ion $^{-1}$ and 1.87 atoms ion $^{-1}$, respectively. ${ }^{12)}$ Since $\mathrm{Nb}$ was less likely to be deposited, the coating weight of the $\mathrm{Zn}-\mathrm{Nb}$ films decreased with increasing $\mathrm{Nb}$ area ratio of the target.

\subsection{Structure of $\mathbf{Z n}-\mathrm{Nb}$ Films}

Figure 3 shows the SEM and EPMA images of $\mathrm{Zn}-\mathrm{Nb}$ films with various compositions. Platelet crystals and smooth areas were observed in $\mathrm{Zn}-\mathrm{Nb}$ films. With increasing $\mathrm{Nb}$ content of the film, smooth areas increased, resulting in a smooth surface all over film at $\mathrm{Nb}$ content exceeding $30 \mathrm{mass} \%$. As can be seen from the characteristic X-ray images of $\mathrm{Zn}$ and $\mathrm{Nb}$, the $\mathrm{Zn}$ content was higher in the platelet crystals than in the smooth areas. $\mathrm{Zn}$ and $\mathrm{Nb}$ were homogeneously distributed over the smooth areas. The platelet crystals became perpendicular to the substrate with increasing $\mathrm{Nb}$ content of the film as shown in Fig. 3(d).

Figure 4 shows the $\mathrm{X}$-ray diffraction patterns of $\mathrm{Zn}-\mathrm{Nb}$ films. X-ray diffraction analysis was carried out changing
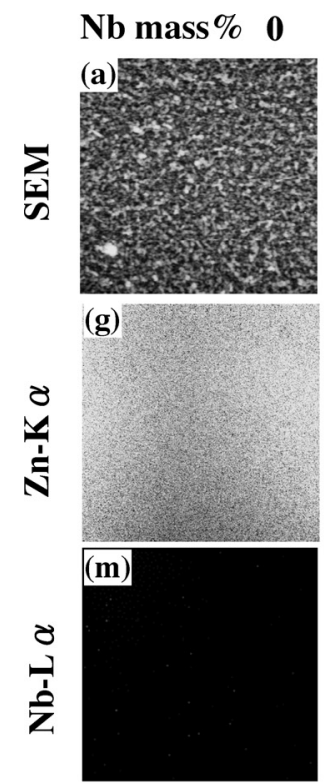

3.5
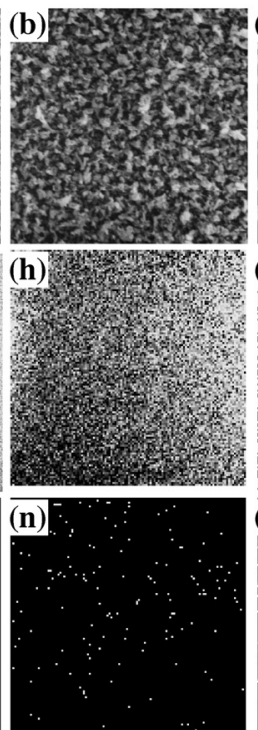

7.6
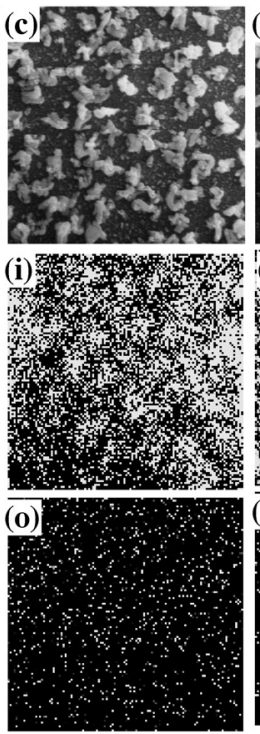

13
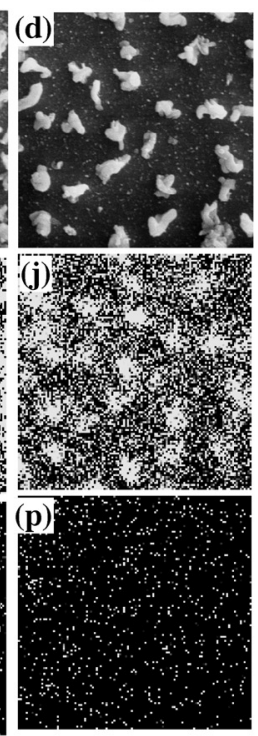

32
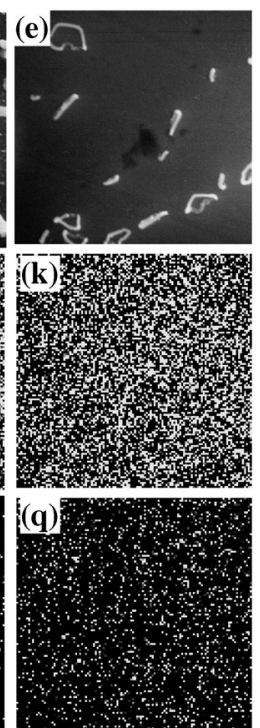

53

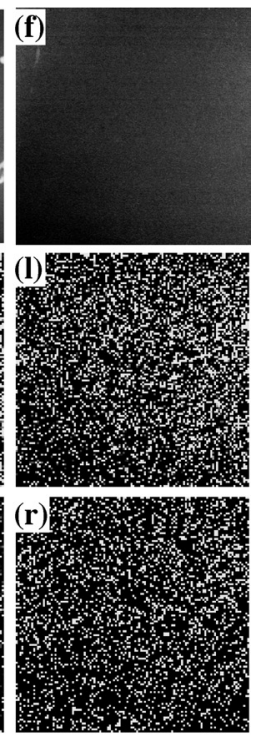

$\mathbf{5} \mu \mathbf{m}$

Fig. 3. EPMA images of $\mathrm{Zn}-\mathrm{Nb}$ films with various compositions. 


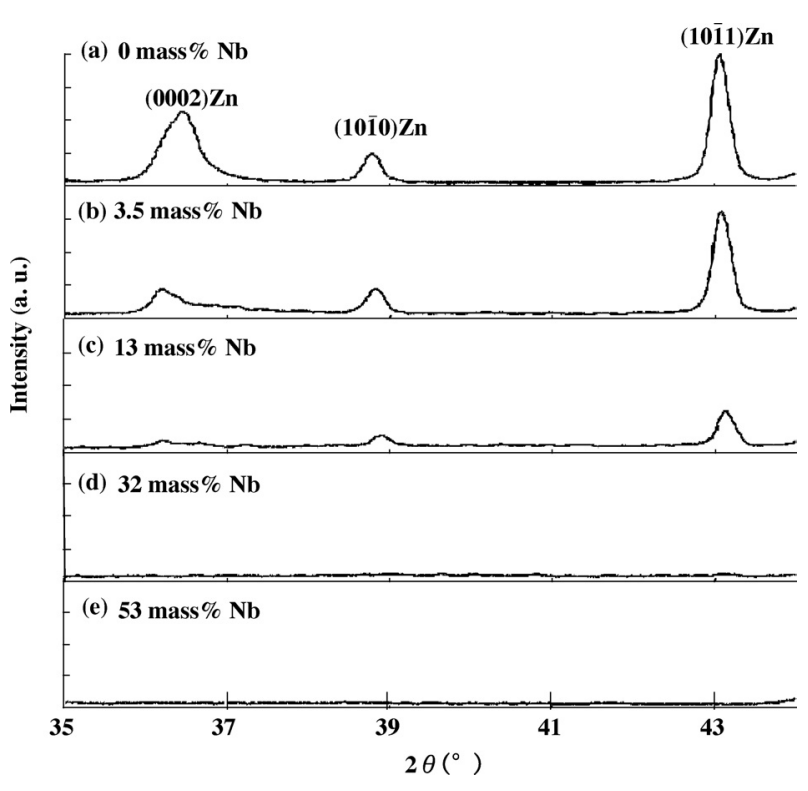

Fig. 4. X-ray diffraction patterns of $\mathrm{Zn}-\mathrm{Nb}$ films with various compositions.

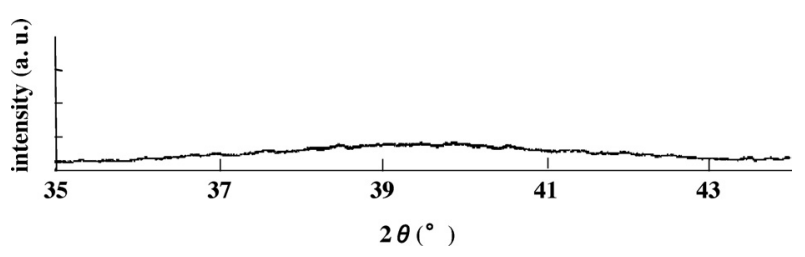

Fig. 5. X-ray diffraction pattern of $\mathrm{Zn}-48$ mass $\% \mathrm{Nb}$ film with coating weight of $2.4 \mathrm{~g} / \mathrm{m}^{2}$.

$2 \theta$ from $30^{\circ}$ to $130^{\circ}$. Figure 4 highlights the result in the low diffraction angle region where the intensity of $\mathrm{Zn}$ was very strong. The $\mathrm{Zn}$ diffraction peaks of the (0002), (1010) and (1011) were observed in $\mathrm{Nb}$-free $\mathrm{Zn}$ film as shown in Fig. 4(a). The intensities of these diffraction peaks decreased with increasing $\mathrm{Nb}$ content in the film, and the peaks disappeared when the $\mathrm{Nb}$ content exceeded 30 mass $\%$. On the other hand, no diffraction peak for $\mathrm{Nb}$ was observed, even when $\mathrm{Nb}$ content exceeded 50 mass $\%$. The X-ray diffraction pattern of $\mathrm{Zn}-48$ mass $\% \mathrm{Nb}$ with a coating weight of $2.4 \mathrm{~g} / \mathrm{m}^{2}$ is shown in Fig. 5. This X-ray diffraction spectrum showed a clear halo pattern characteristic of an amorphous structure. In addition, $\mathrm{Zn}-$ 48 mass $\% \mathrm{Nb}$ resulted in a smooth surface in all over the film. The disappearance of X-ray diffraction peaks when $\mathrm{Nb}$ content exceeded 30 mass\% (Fig. 4) appears to be attributable to a change in film structure to the amorphous type. It has been reported that the alloys which form intermetallic compounds are more likely to become amorphous. ${ }^{13)}$ With $\mathrm{Zn}-\mathrm{Nb}$ alloys, many intermetallic compounds, such as $\mathrm{NbZn}, \mathrm{NbZn}_{1.5}, \mathrm{NbZn}_{2}, \mathrm{NbZn}_{3}, \mathrm{NbZn}_{7}$ and $\mathrm{NbZn}_{15}$ have been reported, ${ }^{14)}$ suggesting that $\mathrm{Zn}-\mathrm{Nb}$ alloys become amorphous over a wide range of composition.

As shown in Fig. 3, the number of platelet crystal decreased with increasing $\mathrm{Nb}$ content in the film, resulting in a smooth surface over the entire film at $\mathrm{Nb}$ content exceeding $30 \mathrm{mass} \%$. The intensities of X-ray diffraction peaks decreased with increasing $\mathrm{Nb}$ content in the film, indicating that $\mathrm{Zn}-\mathrm{Nb}$ film became amorphous at $\mathrm{Nb}$ content exceeding 30 mass\%, as illustrated in Fig. 4. From these results,

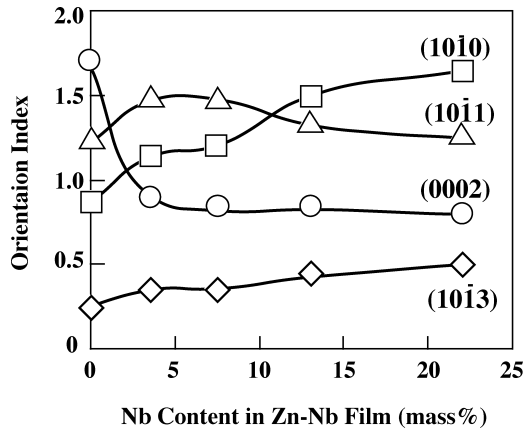

Fig. 6. Relationship between $\mathrm{Nb}$ content and the crystal orientation of $\mathrm{Zn}-\mathrm{Nb}$ films.

the smooth area and the platelet crystals of $\mathrm{Zn}-\mathrm{Nb}$ films appear to correspond to the amorphous phase and Zn crystals, respectively. Both the smooth areas and the platelet crystals were present in $\mathrm{Zn}-7.6$ mass $\% \mathrm{Nb}$ and $\mathrm{Zn}-13$ mass $\% \mathrm{Nb}$ films, suggesting that these films are composed of the amorphous phase and $\mathrm{Zn}$ crystals.

Figure 6 shows the crystal orientation indices of $\mathrm{Zn}$ in $\mathrm{Zn}-\mathrm{Nb}$ films. The preferred orientation of (0002)Zn plane was observed in the $\mathrm{Nb}$-free $\mathrm{Zn}$ film. However, in $\mathrm{Zn}$ 3.5 mass $\% \mathrm{Nb}$ film, the crystal orientation index of $(0002) \mathrm{Zn}$ is significantly smaller than that of $\mathrm{Nb}$-free $\mathrm{Zn}$ film and those of (1011) and (1010)Zn are larger. On further increasing the $\mathrm{Nb}$ content in the films, the crystal orientation index of $(10 \overline{10}) \mathrm{Zn}$ increased. When the preferred orientation of $\mathrm{Zn}$ crystal is the (1010) plane, (0002), the $\mathrm{Zn}$ basal plane of the hcp structure, is vertical to the substrate: in other words, the hexagonal $\mathrm{Zn}$ platelets are perpendicular to the steel substrate. In $\mathrm{Zn}-13$ mass $\% \mathrm{Nb}$ film, the platelet crystals were perpendicular to the substrate, as shown in Fig. 3, which agrees with the assumption that the platelet crystals

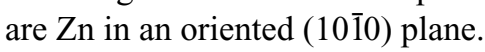

With regard to the crystal orientation of films produced by PVD, a gas-adsorptive inhibition model has been reported. ${ }^{15,16)}$ According to this model, when the concentration of adsorptive inhibitors such as argon gas is low, films grow perpendicularly to a plane with high surface energy, resulting in the preferred orientation of the plane with low surface energy. On increasing the concentration of the adsorptive inhibitor, the inhibitor is preferentially adsorbed onto the plane with high surface energy, thus suppressing any growth vertical to that plane, resulting in the preferred orientation of a plane with high surface energy. Assuming $\mathrm{Nb}$ to be the adsorptive inhibitor in the growth of $\mathrm{Zn}$ films in this study, $\mathrm{Nb}$-free $\mathrm{Zn}$ film more rapidly grows perpendicularly to high energy surface, the (1010)Zn plane, due to the low concentration of adsorptive inhibitor, resulting in the preferred orientation of low energy surface, the (0002)Zn plane. On increasing the $\mathrm{Nb}$ content of the film, the $\mathrm{Nb}$ is adsorbed onto high energy surface, the $(10 \overline{10}) \mathrm{Zn}$ plane and inhibits growth vertical to the (1010)Zn plane, finally resulting in the preferred orientation of the (1010)Zn plane. As described above, the crystal orientation of $\mathrm{Zn}$ can be explained by an adsorptive inhibition model based on the assumption that $\mathrm{Nb}$ acts as an adsorptive inhibitor in the same way as argon gas.

The X-ray diffraction patterns of (0002) and (1010)Zn plane were shifted to the small $2 \theta$ and large $2 \theta$ directions, 




Fig. 7. Relationship between $\mathrm{Nb}$ content and the spacing of $\mathrm{Zn}$ lattice planes.

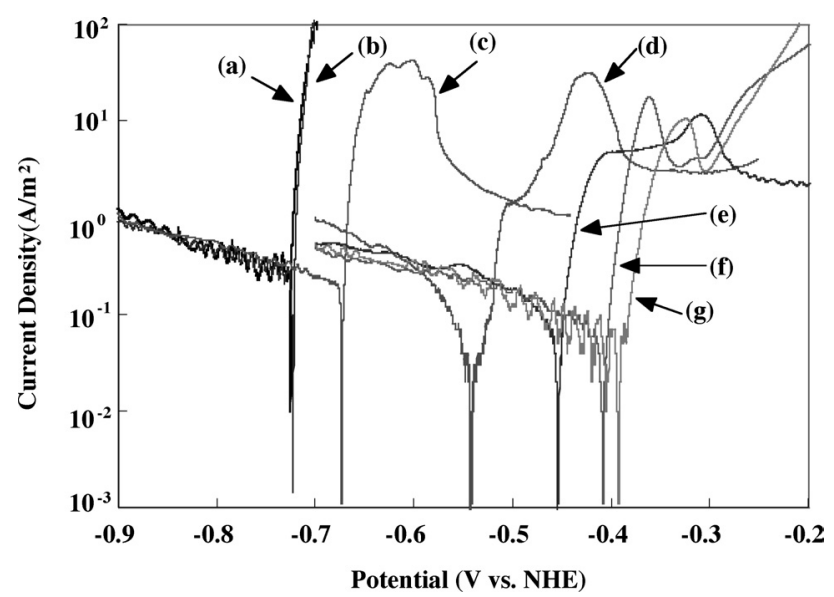

Fig. 8. Polarization curves of $\mathrm{Zn}-\mathrm{Nb}$ films of various compositions in $3 \% \mathrm{NaCl}$ solution. [ $\mathrm{Nb}$ content in film (mass $\%$ ), (a): 0, (b): 2.9, (c): 7.2, (d): 13, (e): 23, (f): 32, (g): 53.]

respectively, with increasing $\mathrm{Nb}$ content in the film, as shown in Fig. 4. The relationship between the $\mathrm{Nb}$ content in the film and the spacings of (0002) and (1010) Zn lattice planes was therefore investigated. The results are shown in Fig. 7. The spacing of the (0002) and (1010)Zn lattice planes based on JCPDS are also described for reference in Fig. 7. In Nb-free $\mathrm{Zn}$ film, the spacing of the (0002)Zn lattice planes was slightly smaller than the JCPDS value, while that of $(10 \overline{1} 0) \mathrm{Zn}$ lattice planes was larger than the JCPDS value. In short, the crystal of $\mathrm{Zn}$ films produced by sputtering was slightly reduced in the direction of $c$-axis of the hcp structure. The spacing of (0002)Zn lattice planes became identical to that of the JCPDS value in $\mathrm{Zn}$ $3.5 \mathrm{mass} \% \mathrm{Nb}$ film and increased with increasing $\mathrm{Nb}$ content in the film. On the other hand, the spacing of (1010) Zn lattice planes decreased with increasing $\mathrm{Nb}$ content in the film. Although phase diagrams show no region for the formation of a solid solution of $\mathrm{Nb}$ in $\mathrm{Zn},{ }^{14)}$ it can be presumed from the observed changes in spacing of the (0002) and $(10 \overline{1} 0) \mathrm{Zn}$ lattice planes that a solid solution of $\mathrm{Nb}$ in $\mathrm{Zn}$ is formed.

\subsection{Polarization Property of $\mathbf{Z n}-\mathbf{N b}$ Films}

Figure 8 shows the polarization curves of $\mathrm{Zn}-\mathrm{Nb}$ film in $3 \% \mathrm{NaCl}$ solution. There were no differences in polarization curves between $\mathrm{Nb}$-free $\mathrm{Zn}$ film and $\mathrm{Zn}-2.9 \mathrm{mass} \% \mathrm{Nb}$ film, while the polarization curves were shifted to the noble direction with increasing $\mathrm{Nb}$ content exceeding 7.2 mass $\%$. At an $\mathrm{Nb}$ content exceeding 7.2 mass $\%$, anodic current den-

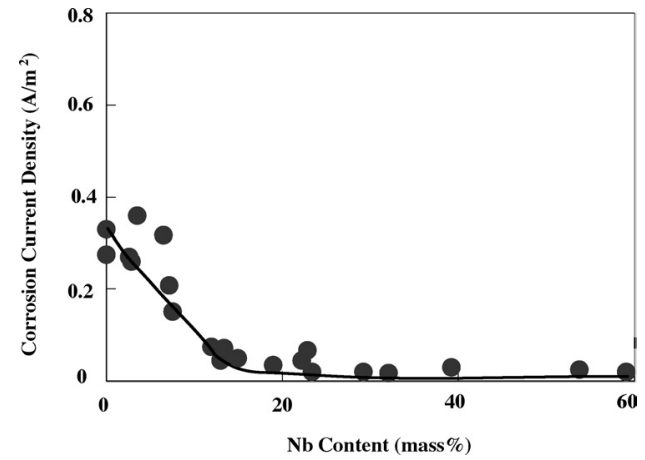

Fig. 9. Relationship between $\mathrm{Nb}$ content and the corrosion current density of $\mathrm{Zn}-\mathrm{Nb}$ films in $3 \% \mathrm{NaCl}$ solution.

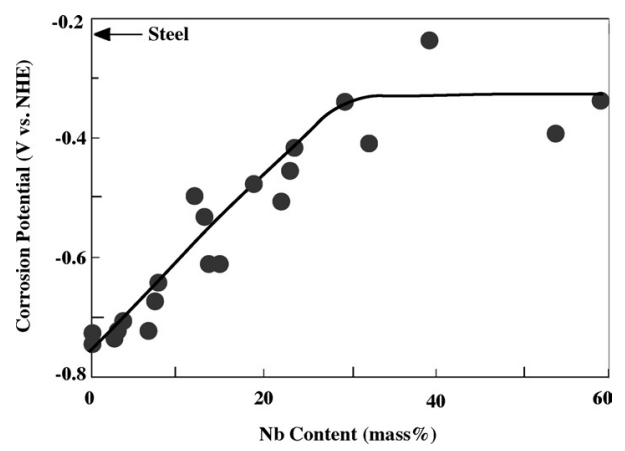

Fig. 10. Relationship between $\mathrm{Nb}$ content and the corrosion potential of $\mathrm{Zn}-\mathrm{Nb}$ films in $3 \% \mathrm{NaCl}$ solution.

sities of $\mathrm{Zn}-\mathrm{Nb}$ films reached the maximum and then decreased. This trend suggests the formation of passivated films.

Figure 9 shows the corrosion current densities of $\mathrm{Zn}-\mathrm{Nb}$ films determined from the polarization curves. The corrosion current density gradually decreased with increasing $\mathrm{Nb}$ content in the film, and leveled off at $\mathrm{Nb}$ content above $30 \mathrm{mass} \%$. This result corresponds to the change in structure of $\mathrm{Zn}-\mathrm{Nb}$ films from platelet crystals to amorphous. $\mathrm{Zn}$ platelet crystals appear to dissolve readily. It is known that amorphous films show excellent corrosion resistance due to their homogeneous structure free from grain boundaries, dislocations, or heterogeneity of composition. ${ }^{17)}$ The $\mathrm{Zn}-\mathrm{Nb}$ films produced by sputtering in this study also showed optimal corrosion resistance when they have an amorphous structure.

Figure 10 shows the corrosion potential of the steel sheet with $\mathrm{Zn}-\mathrm{Nb}$ films determined from the polarization curves. The corrosion potentials were shifted to more noble direction with increasing $\mathrm{Nb}$ content in the film, and leveled off at $\mathrm{Nb}$ content above 30 mass $\%$ in an amorphous structure. The corrosion potentials of $\mathrm{Zn}-\mathrm{Nb}$ films were less noble than that of steel sheet at all $\mathrm{Nb}$ contents, indicating that $\mathrm{Zn}-\mathrm{Nb}$ films act as a sacrificial anode that protect the steel sheet.

\section{Conclusions}

The structure and polarization properties of $\mathrm{Zn}-\mathrm{Nb}$ films formed on steel sheet by sputtering were investigated using SEM, EPMA, X-ray diffraction and electrochemical techniques. The following results were obtained. The number of $\mathrm{Zn}$ plate-like crystals in $\mathrm{Zn}-\mathrm{Nb}$ films decreased with in- 
creasing $\mathrm{Nb}$ content, resulting in a smooth surface over the entire film at $\mathrm{Nb}$ content of $30 \mathrm{mass} \%$ and above. The preferred orientation plane of $\mathrm{Zn}$ plate-like crystals was (0002) at $0 \mathrm{mass} \% \mathrm{Nb}$, while the orientation indices of $(10 \overline{1} 1)$ and $(10 \overline{1} 0) \mathrm{Zn}$ increased with increasing $\mathrm{Nb}$ content. This variation of orientation can be explained by the adsorptive inhibition model, assuming that $\mathrm{Nb}$ acts as an adsorptive inhibitor. At 30-60 mass \% Nb, the X-ray diffraction spectra showed a halo pattern characteristic of an amorphous structure. The corrosion current of $\mathrm{Zn}-\mathrm{Nb}$ films, which was determined by polarization curves in $3 \% \mathrm{NaCl}$ solution, decreased with increasing $\mathrm{Nb}$ content to reach their minimum value at $30-60$ mass $\% \mathrm{Nb}$ in an amorphous structure.

\section{REFERENCES}

1) T. Kanamaru, S. Suzuki and K. Arai: Proc. of 2nd Int. Conf. On Zinc and Zinc Alloy Coated Steel Sheet (GALVATECH'92), ISIJ, Tokyo, (1992), 331.

2) A. Takahashi, Y. Miyoshi and T. Hada: J. Electrochem. Soc., 141 (1994), 954.

3) H. Nakano, S. Oue, F. Yoshinaga, T. Akiyama and H. Fukushima: $J$. Surf. Finish. Soc. Jpn., 54 (2003), 523.
4) K. Nishimura, H. Shindo, H. Nomura and K. Kato: Tetsu-to-Hagané, 89 (2003), 174.

5) K. Nishimura amd H. Shindo: CAMP-ISIJ, 9 (1996), 1278.

6) K. Nishimura, S. Shimazu, H. Nomura, H. Shindo, K. Asai and H. Matsuda: CAMP-ISIJ, 16 (2003), 1507.

7) J. Kawafuku, J. Katoh, M. Toyama, H. Nishimoto, K. Ikeda and H. Satoh: Tetsu-to-Hagané, 77 (1991), 995.

8) H. Satoh: 138TH-139TH Nishiyama Memorial Seminar, Recent Progress and Future Trend of Surface Treatment Technology, ISIJ, Tokyo, (1991), 101.

9) H. Nishimoto: CAMP-ISIJ, 1 (1988), 1631

10) K. Ikeda: CAMP-ISIJ, 1 (1988), 1632.

11) K. S. Willson and J. A. Rogers: Tech. Proc. Am. Electroplaters Soc., 51 (1964), 92.

12) K. Kanaya, K. Hojou, K. Koga and K. Yoki: Jpn. J. Appl. Phys., 12 (1973), 1297.

13) T. Watanabe and Y. Shimizu: Tetsu-to-Hagané, 76 (1990), 1597.

14) R. A. Meussner and R. J. Goode: Trans. Metall. Soc. AIM, 233 (1965), 661.

15) Y. Hasegawa, M. H. Lee, M. Okido and T. Oki: J. Surf. Finish. Soc. Jpn., 44 (1993), 131.

16) H. Matsutake, K. Baba and M. Hasaka: J. Surf. Finish. Soc. Jpn., 43 (1992), 579

17) K. Masumoto and T. Watanabe: Amorphous Plating and the Application, Nikkan Kogyo, Tokyo, (1990), 242. 